\title{
Isolation, Authentication and Evaluation of Rhizobial Isolates from the Soils of North-West Himalayas in French Bean (Phaseolus vulgaris L.)
}

\author{
Saroj Kumar Yadav ${ }^{1 *}$, K.P. Raverkar ${ }^{1}$, Ramesh Chandra ${ }^{1}$, \\ Navneet Pareek ${ }^{1}$ and Subhash Chandra ${ }^{2}$
}

${ }^{1}$ Department of Soil Science, ${ }^{2}$ Departemt of Agronomy, College of Agriculture, G.B. Pant University of Agriculture and Technology, Pantnagar, Uttarakhand, 263145, India

*Corresponding author

Keywords

French bean, Rhizobium, Effectiveness,

Nodulation, Total dry biomass

Article Info

Accepted:

xx November 2018

Available Online:

xx December 2018

\section{A B S T R A C T}

Nodulation ability and effectiveness of native rhizobia from the seven districts of Uttarakhand in French bean was determined. Total of 50 rhizobial isolates separated from the nodules were evaluated for their ability to form nodules and effectiveness under net house and glass house conditions. These isolates exhibited typical characteristics of Rhizobium sp. on yeast extract mannitol agar media supplemented with Congo red. Out of fifty isolates 36 were authenticated as Rhizobium based on their ability to nodulate French bean. French bean inoculation with the rhizobial isolates significantly increased the dry shoot, root and total biomass; and shoot: root ratio. The dry shoot, root and total biomass produced due to inoculation with rhizobial isolate RA6 was highest among all the rhizobial isolates. The dry shoot biomass produced due to inoculation with rhizobial isolates RA6, RL21 and RA8 was statistically at par with that of reference strain MTCC 10096. The inoculation of French bean with rhizobial isolate RA6 produced total dry biomass significantly higher by 154.4 per cent over reference strain i.e. MTCC 10096.Our results demonstrated the presence of native rhizobia in soils of N-W Himalayas capable of nodulating French bean that are either superior or at par with reference strain in improving the overall growth and synthesis of higher biomass in French bean.

\section{Introduction}

Sustainable soil fertility management is a key to food production and environmental stability (Lal, 2009). Historically, legume crops such as common bean (Phaseolus vulgaris L.) have played an important role in soil fertility through symbiotic nitrogen fixation, enhancement of soil organic matter, and prevention of nutrient leaching (Mothapo,
2011 and Mothapo et al., 2009). Among the legumes, French bean (Phaseolus vulgaris L.) is used profusely by the common people as an alternative diet of protein. It is very nutritious and rich in protein $(22.9 \%)$. It contains 1.2 per cent fat, 60.6 per cent carbohydrates and a large number of minerals like Ca (260 mg 100 $\mathrm{gm}^{-1}$ of seed), $\mathrm{P}$ (101 mg $100 \mathrm{~g}^{-1}$ of seed) and Fe (5.8 mg $100 \mathrm{~g}^{-1}$ of seed). French bean is sparsely nodulated throughout the India 
including North-West Himalayas putting it to disadvantage of biologically fixed nitrogen and thus responds to the increased levels of nitrogen (Sharma et al., 2003).No nodules in French bean were synthesized in the soils of District Nainital, Uttarakhand, however 25-75 percent of soils from other districts supported the nodulation in French bean (Raverkar, 2016). In India, it is grown on an area of about 1 lakh hectare mainly in the states of Maharashtra, Jammu and Kashmir, Himachal Pradesh, Uttarakhand, Nilgiri (Tamil Nadu), Palni (Kerala) hills, Chickmagalur (Karnataka) and Darjeeling hills (West Bengal). The sparse nodulation in French bean may be mainly due to below threshold level of specific rhizobial cells in soil at the time of sowing. Recently different rhizobial strains have demonstrated various other plant growth promoting activities in addition to biological nitrogen fixation (BNF). Deficiency of N, the major nutrient taken up by French bean in the largest amounts (Vance, 2001), is a major constraint to crop productivity on many smallholder farming systems (Schwartz, 1989). Generally smallholder farmers, rarely apply nitrogenous fertilizers in bean production, relying mainly on the ability of the bean to fix its own nitrogen and natural soil fertility. It is well documented that the beans are sparsely nodulated and thus fix atmospheric nitrogen poorly (Hardorson, 1993). In the absence of compatible rhizobia and/ or soil containing below threshold level of specific rhizobia, inoculation of legumes with efficient rhizobia is must (Catroux et al., 2001). Commercial inoculants used still contain exotic cultures from United States of America (Waswa, 2014) or from other sources which may not be well adapted and efficient under local conditions. It is therefore hypothesized that the soils of N-W Himalayas of Uttarakhand might be harbouring rhizobial strains capable of nodualting and fixing atmospheric nitrogen efficiently in French bean. The present investigation was therefore carried out to determine the infectiveness and effectiveness of native rhizobial isolates from N-W Himalayan region of Uttarakhand nodulating and improving the growth of French bean.

\section{Materials and Methods}

Soil samples from the seven districts located at varying altitudes ranging from approximately $300 \mathrm{~m}$ to $4000 \mathrm{~m}$ MSL of N-W Himalayas of Uttarakhand were collected. The details of the sites of soil samples collected are given in Table 1. Two to three kilograms of soil sample from each location was brought to the laboratory and stored in cool place. The collected samples were partitioned into two parts. One part was put at cool place as such while another part of the soil sample was air dried, processed and sieved through $2 \mathrm{~mm}$ sieve for chemical analyses. The chemical properties of the soils are depicted in Table 1.

\section{Raising of Rajmash plants for isolation of Rhizobium}

Rhizobial isolates from different soils were isolated by employing trap method using French bean as host. The $500 \mathrm{~g}$ capacity thermo coal glasses were filled with various soil samples after separation of roots pieces, stones and pebbles and three surface sterilized seeds of French bean were dibbled aseptically at a depth of $2-3 \mathrm{~cm}$ in respective pots. After germination, two healthy plants were allowed to grow in net house for 60 days and the nodules formed were separated for isolation of rhizobial isolates.

\section{Isolation and authentication of Rhizobium from nodule of French bean}

Rhizobium isolates were isolated from healthy and pinkish nodules. The nodules were washed gently but thoroughly with tap water to remove all the soil particles and surface 
sterilized by exposing to 70 per cent ethanol for 30 seconds followed by 3 per cent hydrogen peroxide $\left(\mathrm{H}_{2} \mathrm{O}_{2}\right)$ for $2 \mathrm{~min}$. Subsequently the surface sterilized nodules were rinsed with sterilized water. Each surface sterilized nodule was crushed separately in a 1 $\mathrm{ml}$ of sterilized water with a sterilized pair of forceps and a loopfull suspension was streaked on yeast extract mannitol agar plates (YEMA) (Vincent, 1970) containing congo red and incubated at $28 \pm 2^{0} \mathrm{C}$ for $48-120$ hours. The probable rhizobial isolates were authenticated by testing the ability to nodulate French bean employing plant infection test in Leonard jars.

\section{Preparation of Leonard jars}

The beer bottles were cut into two halves. After fitting the cotton wick into the neck of the bottle, it was inverted and filled with dry sand and neck was placed into another half bottom of the bottle.

The bottom portion was then filled with 200 $\mathrm{ml}$ Hoagland's solution and allowed the sand filled in upper part to be completely moistened by capillary action of the wick in approximately. The assemblies were then covered with an aluminum foil and autoclaved thrice at $15 \mathrm{PSI}\left(121^{\circ} \mathrm{C}\right)$ for 3 hours.

\section{Sowing of seeds}

French bean seeds were surface sterilized by immersing in one per cent mercuric chloride solution for 3 minutes and subsequently rinsing with five changes of sterile distilled water. The surface sterilized seeds were imbibed by soaking for overnight and then rinsed twice with sterile water and transferred aseptically to 0.75 per cent (w/v) water agar plates and germinated for 5-7 days in a BOD incubator at $28-30^{\circ} \mathrm{C}$. Two germinated seeds having equal radical length i.e. of $0.5-1 \mathrm{~cm}$ long were transferred carefully with the help of sterilized forceps in well-spaced holes in the rooting medium to a depth of $2-2.5 \mathrm{~cm}$ in each autoclaved Leonard jars.

\section{Inoculation of seeds and maintenance of Leonard jars}

Each germinated seed was covered with sterile sand and inoculated with respective rhizobial isolates immediately with $2 \mathrm{ml}$ of the bacterial inoculum at $\log$ phase of growth having $10^{8}$ cfu $\mathrm{ml}^{-1}$. These jars were wrapped with aluminum foil around the lower part of the jar to avoid any algal growth in nutrient solution. After cotyledons emergence the jars were placed in net house for the growth of plants.

\section{Evaluation of efficacy of French bean rhizobial isolates}

Authenticated French bean rhizobial isolates were screened based on their effectiveness at flowering in sand culture under net house conditions for the synthesis of dry shoot, root and total biomass.

\section{Experimental design and treatments}

The experiment for authentication of rhizobial isolates was laid in Completely Randomized Design (CRD) with Fifty two treatments comprising 50 probable rhizobial isolates, one reference strain and one uninoculated control and three replications (Table 2). Similarly, the experiment for evaluation of authenticated rhizobial isolates was also conducted employing CRD with thirty-eight treatments (35 authenticated rhizobial isolates, reference strain and uninoculated control with and without nitrogen) in three replications during 2016-17in Net house and Glass house (Table $3)$.

\section{Statistical analysis}

Means of treatments of isolates' effects were separated based on least significant difference 
(LSD) using analysis of variance (ANOVA) technique for completely randomized design (CRD) using SPSS. The LSD values were tested at $5 \%(P \leq 0.05)$ level of probability.

\section{Results and Discussion}

\section{Authentication of French bean bacterial isolates}

The bacterial isolates separated from nodules of French bean grown in various soils of different districts of Uttarakhand, were authenticated on the basis of infectiveness i.e. presence or absence of nodules in roots of French bean. Dhull and Gera (2017) had isolated 158 cluster bean rhizobial isolates using trap plant method from sixty seven soil samples from three districts of Haryana.

Out of fifty French bean bacterial isolates obtained from different soils of $\mathrm{N}-\mathrm{W}$ Himalayas of Uttarakhand thirty five isolates along with the reference strain MTCC 10096 produced the nodules in French bean (Phaseolus vulgaris) under gnotobiotic conditions (Table 2). Fourteen isolates viz; RD20-1, RK4, RK15-1, RA17, RB2-2, RB7, RB8-5R, RC15, RP5-3, RP5-4, RPB-4, RPB5C, RL5 and RL11 did not nodulate the host plant under gnotobiotic conditions. The isolates capable of producing nodules in French bean under controlled conditions considered as French bean Rhizobium isolates. These observations are consistent with Bala et al., (2013), who reported that appropriate rhizobial isolates nodulate and fix di-nitrogen in French bean and that each isolate was able to form nodules with the host plant was identified as Rhizobium. There was no nodulation in the uninoculated control demonstrated that aseptic conditions were met in the experimental set up and maintenance of the plants in the net house (Bala et al., 2013). This is concordant with a study of Elbana et al., (2009) who demonstrated no disparity in symbiotic effectiveness among indigenous rhizobial strains linked with particular host plant.

Evaluation of efficacy of French bean rhizobial isolates

On the basis of nodulation ability 35 authenticated rhizobial isolates along with reference strain MTCC 10096 were selected for evaluation or screening in terms of plant dry matter production i.e. effectiveness. The effectiveness of the selected rhizobial isolates varied significantly in synthesis of dry matter and shoot: root ratio (Table 3 ).

\section{Dry matter synthesis}

An inoculation of French bean with various rhizobial isolates significantly influenced the dry shoot, root and total biomass of French bean over uninoculated control with and without nitrogen (Table 3). The dry shoot biomass produced due to inoculation with rhizobial isolates was ranged between 0.11 and $0.76 \mathrm{~g} \mathrm{plant}^{-1}$ the highest being produced due to inoculation with rhizobial isolates RA6 followed by RL21, MTCC10096, RA8 and RK3-1; and the lowest in uninoculated control without nitrogen. The dry shoot biomass produced due to inoculation with rhizobial isolate RA6 was significantly higher by 375 and 590 per cent over uninoculated control with and without nitrogen, respectively. The dry shoot biomass produced due to inoculation with rhizobial isolates RA6, RL21 and RA8 was statistically at par with that of due to inoculation with reference strain MTCC 10096.

The range of dry root biomass of French been laid between 0.10 and $0.66 \mathrm{~g}$ plant $^{-1}$. Inoculation of French bean with rhizobial isolate RA6 produced highest dry root biomass followed by reference strain MTCC 10096, RA13-2 and RD19 while the lowest 
was produced in uninoculated control without nitrogen. Dry root biomass produced due to inoculation with rhizobial isolate RA6 was higher by 560 and 24 per cent over uninoculated control without nitrogen and reference strain MTCC 10096, respectively.

Total dry biomass produced due to inoculation with various rhizobial isolates ranged between 0.21 and $1.42 \mathrm{~g} \mathrm{plant}^{-1}$. The highest total dry biomass was produced due to inoculation with rhizobial isolate RA6 followed by MTCC 10096, RL 21 and RA8 and the lowest in uninoculated control without nitrogen. The inoculation of French bean with rhizobial isolate RA6 produced total dry biomass was significantly higher by 154.4 per cent over reference strain i.e. MTCC 10096.

There were significant differences in shoot, root and total dry biomass of $P$. vulgaris inoculated with variable rhizobial isolates. Nodulated plants had higher shoot dry biomass and root dry biomass than the non nodulated plants. The significant differences in the shoot dry biomass showed clear differences in the ability of the isolates to fix nitrogen and are among the preferred methods for determining symbiotic effectiveness of rhizobial isolates (Sharma et al., 2003). The ability of the isolates to fix nitrogen was also demonstrated by observable differences in the plant colour and nodulation (Muthini et al., 2014).

The dark green color observed in some of the inoculated treatments and not in the uninoculated control showed effective symbiotic relationship between the French bean plant and some of the isolates after the six week of development. This corresponds well with the work of Delic et al., (2010).

Table.1 Chemical properties of soil samples for Rhizobium isolation

\begin{tabular}{|c|c|c|c|c|c|c|c|c|}
\hline $\begin{array}{l}\text { Sl. } \\
\text { No. }\end{array}$ & Sites & $\begin{array}{l}\text { Altitude } \\
\text { (m) }\end{array}$ & pH & $\begin{array}{c}\mathrm{EC} \\
\left(\mathrm{dS} \mathrm{m}^{-1}\right)\end{array}$ & $\begin{array}{l}\text { SOC } \\
(\%)\end{array}$ & $\begin{array}{l}\text { Avail. N } \\
\left(\mathrm{kg} \mathrm{ha}^{-1}\right)\end{array}$ & $\begin{array}{l}\text { Avail. P } \\
\left(\mathrm{kg} \mathrm{ha}^{-1}\right)\end{array}$ & $\begin{array}{l}\text { Avail. } \\
\text { K (kg } \\
\left.\text { ha }^{-1}\right)\end{array}$ \\
\hline 1. & Dehradun & $>2000$ & 7.5 & 0.77 & 0.67 & 225 & 22.2 & 208.2 \\
\hline 2. & Kotdwar & $\begin{array}{l}500- \\
1700\end{array}$ & 7.2 & 0.67 & 0.65 & 217 & 24.1 & 198.2 \\
\hline 3. & Pithoragarh & $\begin{array}{l}1500- \\
2000\end{array}$ & 5.6 & 0.54 & 0.77 & 274 & 16 & 230 \\
\hline 4. & Bageshwar & $\begin{array}{l}950- \\
1300\end{array}$ & 5.7 & 0.46 & 0.87 & 254 & 22 & 224 \\
\hline 5. & Chamauli & $\begin{array}{l}2000- \\
4000\end{array}$ & 6.6 & 0.55 & 0.82 & 224 & 21.2 & 188.6 \\
\hline 6. & Almora & $\begin{array}{l}1000- \\
1500\end{array}$ & 6.7 & 0.62 & 0.80 & 252 & 19 & 245 \\
\hline 7. & $\begin{array}{l}\text { U.S.Nagar } \\
\text { (Phoolbagh) }\end{array}$ & 284.5 & 6.6 & 0.21 & 0.89 & 235 & 21 & 234.5 \\
\hline 8. & $\begin{array}{l}\text { U. S. Nagar (L } \\
\text { Block) }\end{array}$ & 284.5 & 6.1 & 0.54 & 0.95 & 232 & 22 & 238.4 \\
\hline
\end{tabular}


Table.2 Authentication of bacterial isolates from soils of N-W Himalayas of Uttarakhand as French bean Rhizobium employing plant infection test

\begin{tabular}{|c|c|c|c|c|c|}
\hline $\begin{array}{l}\text { Sl. } \\
\text { No. }\end{array}$ & $\begin{array}{l}\text { Isolate } \\
\text { code }\end{array}$ & $\begin{array}{l}\text { Presence/ } \\
\text { absence of } \\
\text { nodule(s) }\end{array}$ & $\begin{array}{l}\text { Sl. } \\
\text { No. }\end{array}$ & Isolate code & $\begin{array}{c}\text { Presence/ } \\
\text { absence of } \\
\text { nodule(s) }\end{array}$ \\
\hline 1. & RD 19 & + & 27. & RB8-1 & + \\
\hline 2. & RD20-1 & - & 28. & RB8-2 & + \\
\hline 3. & RD20-2 & + & 29. & RB8-5R & - \\
\hline 4. & RD20-3 & + & 30. & $\mathrm{RC} 15$ & - \\
\hline 5. & RK3-1 & + & 31. & RP5-1 & + \\
\hline 6. & RK3-2 & + & 32. & RP5-2 & + \\
\hline 7. & RK4 & - & 33. & RP5-3 & - \\
\hline 8. & RK8 & + & 34. & RP5-4 & - \\
\hline 9. & RK15-1 & - & 35. & RP11 & + \\
\hline 10. & RK15-2 & + & 36. & RP12 & + \\
\hline 11. & RK19-1 & + & 37. & RPB-1 & + \\
\hline 12. & RK19-2 & + & 38. & RPB-2 & + \\
\hline 13. & RK21-1 & + & 39. & RPB-3 & + \\
\hline 14. & RK21-2 & + & 40. & RPB-4 & - \\
\hline 15. & RA6 & + & 41. & RPB5C & - \\
\hline 16. & RA8 & + & 42. & RL1 & + \\
\hline 17. & RA13-1 & + & 43. & RL3 & + \\
\hline 18. & RA13-2 & + & 44 & RL4 & - \\
\hline 19. & RA13-3 & + & 45. & RL5 & - \\
\hline 20. & RA17 & - & 46. & RL11 & - \\
\hline 21. & RB2-1 & + & 47 & RL12 & + \\
\hline 22. & RB2-2 & - & 48. & RL13 & + \\
\hline 23. & RB2-3 & + & 49. & RL21 & + \\
\hline 24. & RB3-1 & + & 50. & RL22 & + \\
\hline 25. & RB3-2 & + & 51. & $\begin{array}{l}\text { MTCC10096 } \\
\text { (Ref.) }\end{array}$ & + \\
\hline 26. & RB7 & - & 52. & $\begin{array}{l}\text { Uninoculated } \\
\text { control }\end{array}$ & - \\
\hline
\end{tabular}

+: indicates presence of nodule; -: indicates absence of nodule

Ref.: Reference strain: Rhizobium leguminosarum from IMTECH, Chandigarh 
Table.3 Effect of different rhizobial isolates on dry biomass production and Shoot: Root ratio of French bean

\begin{tabular}{|c|c|c|c|c|c|}
\hline $\begin{array}{l}\text { SI. } \\
\text { No. }\end{array}$ & Isolates & $\begin{array}{c}\text { Dry shoot } \\
\text { biomass ( } \mathrm{g} \\
\left.\text { plant }^{-1}\right)\end{array}$ & $\begin{array}{c}\text { Dry root } \\
\text { biomass }(\mathrm{g} \\
\left.\text { plant }^{-1}\right)\end{array}$ & $\begin{array}{c}\text { Total dry } \\
\text { biomass ( } g \\
\left.\text { plant }^{-1}\right)\end{array}$ & $\begin{array}{l}S: R \\
\text { ratio }\end{array}$ \\
\hline 1. & Control & 0.11 & 0.10 & 0.21 & 1.10 \\
\hline 2. & $\mathrm{C}-\mathrm{N}^{+}$ & 0.16 & 0.14 & 0.30 & 1.14 \\
\hline 3. & RD 19 & 0.45 & 0.37 & 0.82 & 1.22 \\
\hline 4. & RD20-2 & 0.35 & 0.28 & 0.63 & 1.25 \\
\hline 5. & RD20-3 & 0.43 & 0.22 & 0.65 & 1.95 \\
\hline 6. & RK3-1 & 0.55 & 0.22 & 0.77 & 2.50 \\
\hline 7. & RK3-2 & 0.23 & 0.26 & 0.49 & 0.88 \\
\hline 8. & RK8 & 0.29 & 0.19 & 0.48 & 1.52 \\
\hline 9. & RK15-2 & 0.28 & 0.29 & 0.57 & 0.97 \\
\hline 10. & RK19-1 & 0.38 & 0.23 & 0.61 & 1.65 \\
\hline 11. & RK19-2 & 0.35 & 0.33 & 0.68 & 1.06 \\
\hline 12. & RK21-1 & 0.34 & 0.35 & 0.68 & 0.97 \\
\hline 13. & RK21-2 & 0.17 & 0.16 & 0.33 & 1.06 \\
\hline 14. & RA6 & 0.76 & 0.66 & 1.42 & 1.15 \\
\hline 15. & RA8 & 0.65 & 0.31 & 0.96 & 2.10 \\
\hline 16. & RA13-1 & 0.21 & 0.23 & 0.44 & 0.91 \\
\hline 17. & RA13-2 & 0.42 & 0.39 & 0.81 & 1.08 \\
\hline 18. & RA13-3 & 0.35 & 0.25 & 0.60 & 1.40 \\
\hline 19. & RB2-1 & 0.34 & 0.17 & 0.51 & 2.00 \\
\hline 20. & RB2-3 & 0.19 & 0.14 & 0.33 & 1.35 \\
\hline 21. & RB3-1 & 0.32 & 0.36 & 0.68 & 0.89 \\
\hline 22. & RB3-2 & 0.27 & 0.28 & 0.56 & 0.96 \\
\hline 23. & RB8-1 & 0.31 & 0.34 & 0.65 & 0.91 \\
\hline 24. & RB8-2 & 0.44 & 0.23 & 0.67 & 1.91 \\
\hline 25. & RP5-1 & 0.35 & 0.20 & 0.55 & 1.75 \\
\hline 26. & RP5-2 & 0.28 & 0.17 & 0.46 & 1.65 \\
\hline 27. & RP11 & 0.22 & 0.11 & 0.33 & 2.00 \\
\hline 28. & RP12 & 0.23 & 0.18 & 0.41 & 1.28 \\
\hline 29. & RPB-1 & 0.23 & 0.12 & 0.35 & 1.92 \\
\hline 30. & RPB-2 & 0.20 & 0.30 & 0.50 & 0.67 \\
\hline 31. & RPB-3 & 0.35 & 0.30 & 0.65 & 1.17 \\
\hline 32. & RL1 & 0.32 & 0.28 & 0.60 & 1.14 \\
\hline 33. & RL3 & 0.33 & 0.18 & 0.52 & 1.83 \\
\hline 34. & RL12 & 0.25 & 0.17 & 0.43 & 1.47 \\
\hline 35. & RL13 & 0.24 & 0.25 & 0.50 & 0.96 \\
\hline 36. & RL21 & 0.73 & 0.27 & 1.00 & 2.70 \\
\hline 37. & RL22 & 0.51 & 0.25 & 0.75 & 2.04 \\
\hline 38. & MTCC10096 & 0.71 & 0.53 & 1.23 & 1.34 \\
\hline \multicolumn{2}{|c|}{ SE m ( $( \pm)$} & 0.02 & 0.01 & 0.04 & 0.13 \\
\hline \multicolumn{2}{|c|}{ C.V (\%) } & 11.54 & 7.86 & 9.98 & 15.45 \\
\hline \multicolumn{2}{|c|}{ LSD $(P \leq 0.05)$} & 0.07 & 0.03 & 0.10 & 0.37 \\
\hline
\end{tabular}




\section{Shoot: root ratio}

The shoot: root ratio influenced significantly due to inoculation with various rhizobial isolates (Table 3). The shoot: root ratio of French bean due to inoculation with various rhizobial isolates was varied between 0.67 and 2.70. Highest shoot: root ratio was produced due to inoculation with rhizobial isolate RL21 followed by RK3-1, RA8 and RB2-1; and the lowest in plant inoculated with RPB-2. The shoot : root ratio recorded due to inoculation with rhizobial isolates RD19, RD20-2, RK8, RK15-2, RK19-1, RA6, RA13-2, RA13-3 and other six isolates was at par with that of recorded due to inoculation with reference strain i.e. MTCC 10096.

More dry matter was partitioned to shoots at the expense of roots during latter half of plant growth. The shoot: root ratio could be the result of a fully functional $\mathrm{N}_{2}$-fixation system as a result of effective nodulation in the net house. Plants having anadequate $\mathrm{N}$ supply from effective, functional nodules on the root, direct biomass predominately to the shoot (Beck, 1996) as seen in the latter half of the plant growth. This could also explain the variation in shoot: root ratio. The shoot: root ratio of plants is not fixed and varied within species specific limits in response to the environment (Mc Michael and Quisenberry, 1991).

The soils of N-W Himalayan region of Uttarakhand harboured the efficient rhizobial isolates capable of nodulating and enhancing the growth of French bean under net house conditions. Various native rhizobial isolates from N-W Himalayas were either superior or at par with the reference strain. The efficient rhizobial isolates of $\mathrm{N}-\mathrm{W}$ Himalayan region of Uttarakhand have the potential to be developed as Rhizobium biofertilizer for French bean. However further studies under uncontrolled conditions are warranted. It would also be of interest to test whether these efficient rhizobial isolates has any other plant growth promoting activity (ies) in addition to the ability to fix atmospheric nitrogen.

\section{Acknowledgements}

The authors are thankful to the Project Coordinator AINP on Soil Biodeversity: Biofertilizer, ICAR-IISS, Bhopal (M.P.) and G. B. Pant University of Agriculture and Technology, Pantnagar, Uttarakhand India for providing the support to undertake the present investigation.

\section{References}

Bala, A., Abaidoo, R. and Woomer, P. 2013. Strain isolation and characterisation protocol. Rhizobia.72: 322-332 httpp: //www N2Africa.org.

Beck, E. H. 1996. Regulation of shoot/root ratio by cytokinins from the roots in Urticadioica: Opinion. Plant Soil185: 312.

Catroux, G., Hartmann, A. and Revellin, C. 2001.Trends in rhizobial inoculant production and use. Plant Soil 230: 2130.

Delic, D., Stajkovic, O., Rasulic, N., Kuzmanovic, D., Josic, D. and Milicic, B.2010. Nodulation and $\mathrm{N}_{2}$-fixation effectiveness of Bradyrhizobium strains in symbiosis with adzuki bean, Vignaangularis. Brazil. Archi. Biol. Technol. 53: 293-299.

Dhull, S. and Gera, R. 2017. Assessing stress tolerant rhizobial isolates of clusterbean (Cyamopsistetragonoloba (L.) Taub.) Retrieved from semi-arid regions of Haryana, India. Inter. J. Curr.Microbiol.Appl. Sci. 6:744-753

Elbanna, K., Elbadry, M., and Gamal-Eldin, H. 2009. Genotypic and phenotypic characterization of rhizobia that nodulatesnapbean (Phaseolus vulgaris 
L) in Egyptian soils. Syst. Appl. Microbiol. 32:522-530.

Hardarson, G. 1993. Methods for enhancing symbiotic nitrogen fixation. Plant Soil 152: $1-17$.

Lal, R. 2009. Soils and food sufficiency. A review. Agron. Sustainab. Develop. 29: 113-133.

McMichael, B. L. and Quisenberry, J. E.1991.Genetic variation for root-shoot relationship among cotton germplasm. Environ. Experimen. Bota. 31: 461-470.

Mothapo, N. V. 2011. Nodulation and rhizobia diversity associated with distinct hairy vetch genotypes (Ph.D. thesis) North Carolina State University (NCSU).

Mothapo, N. V., Grossman, J. M., Maul, J. E., Shi, W. and Isleib, T. 2013. Genetic diversity of resident soil rhizobia isolated from nodules of distinct hairy vetch (Vicia villosa) genotypes. Appl. Soil Ecol. 64: 201-213.

Muthini M., Maingi J. M., Muoma J. O., Amoding A., Mukaminega, D. and Osoro, N. 2014. Morphological assessment and effectiveness of indigenous rhizobia isolates that nodulate $P$. vulgaris in water hyacinth compost testing field in Lake Victoria basin. Ecosphere 4: 718-738.
Raverkar, K. P. 2016. Progress report (201516) of All India Network Project on Soil Biodiversity- Biofertilizers (ICARIISS): G.B. Pant University of Agriculture and Technology, Pantnagar Centre. P.16.

Schwartz, H. F. and Pastor-Corrales, M. A. 1989.Bean Production Problems in the Tropics. Cali, Colombia: CIAT.

Sharma, A., Johri, B. N., Sharma, A. K. and Glick, B. R. 2003. Plant growthpromoting bacterium Pseudomonas sp. strain GRP3 influences iron acquisition in mung bean (Vigna radiata L. Wilzeck). Soil Biol. Biochem. 35: 887894.

Vance, C. P. 2001. Symbiotic nitrogen fixation and phosphorus acquisition. Plant nutrition in a world of declining renewable resources. Plant Physiol.127: 390-397.

Vincent, J. M. 1970. Manual for practical study of root nodule bacteria. IBP Hand Book No. 15, Blackwell, Edinburgh, U. K. 73-97.

Waswa, N. M. 2014. Identifying elite rhizobia for commercial soybean (glycine max) inoculants (M.S. thesis) Nairobi, Kenya: University of Nairobi.

\section{How to cite this article:}

Saroj Kumar Yadav, K.P. Raverkar, Ramesh Chandra, Navneet Pareek and Subhash Chandra. 2018. Isolation, Authentication and Evaluation of Rhizobial Isolates from the Soils of NorthWest Himalayas in French Bean (Phaseolus vulgaris L.). Int.J.Curr.Microbiol.App.Sci. 7(12): 141-149. doi: https://doi.org/10.20546/ijcmas.2018.712.018 